\title{
Vaginal Atrophy and Lichen Sclerosus: A Case Report
}

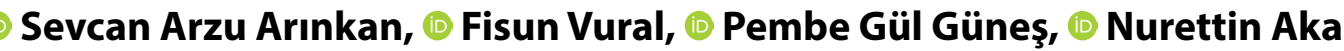

Department of Gynecology and Obstetrics, Haydarpasa Numune Research and Training Hospital, Istanbul, Turkey

\begin{abstract}
Lichen sclerosus (LS) is a benign, progressive, inflammatory disease characterized by epithelial thinning. An 81-year-old woman presented to our clinic with the complaint of difficulty in urination. There were whitish lesions on her vulva. Also, her urethra and vagina were obliterated with an approximately $2 \mathrm{~mm}$ opening. The diagnosis of LS was confirmed with pathological examination. Topical clobetasol propionate and estrogen treatment were prescribed. Three months later, the vagina had an approximately $1.5-\mathrm{cm}$ diameter opening and there was no difficulty in urination. Such cases should be followed up concerning the progression of vulvar cancer. Keywords: Lichen sclerosus; vaginal atrophy; vaginal stenosis.
\end{abstract}

$\mathrm{L}$ ichen sclerosus (LS) is a benign, chronic, progressive, and inflammatory disease characterized by epithelial thinning. It can be seen at all ages, but its incidence increases during prepubertal and postmenopausal period [1]. Although the etiology of LS is not definite, it is thought that genetic, local, and immunologic factors; low estrogen level; and human papillomavirus and Borrelia burgdorferi infections may be the causes.

In LS, keratin 6 and 16 are thought to be responsible for increased cell turnover ${ }^{[2,3]}$. In cases of vulvar LS, the risk of developing squamous cell carcinoma (SCC) increases. In addition, differentiated vulvar intraepithelial neoplasia is a precursor lesion of SCC and is frequently associated with LS (4). Itching and pain are the accompanying symptoms ${ }^{[5]}$. LS frequently (85\%) involves the anogenital region. Clitoris, posterior genitalia, and anorectal region are frequently affected. Lesions are usually white, easily bleeding, papules or plaques. Symptoms such as irritation in the vulva, pain during urination, and pruritus can be seen. Tissue changes in LS cause atrophic changes in the vulvar structure. Invasion of the vagina is not characteristic, but narrowing of the introitus may be observed at varying degrees ${ }^{[6]}$.

We also aimed to discuss the management of patients with LS progressing with vaginal stenosis and advanced anatomic deformity.

\section{Case Report}

An 81-year-old patient who complained about difficulty in urination for nearly 3 years presented to our outpatient clinic. The gravida 4 parity 2 patient who entered into postmenopausal period nearly 40 years ago had hypertension and epilepsy.

Gynecologic examination revealed white areas on the vulva, and the epidermis was atrophic and white. Vaginal examination could not be performed due to the presence of a vaginal fissure. On inspection, the labia were effaced, and

Correspondence (iletişim): Sevcan Arzu Arınkan, M.D. Department of Gynecology and Obstetrics, Haydarpasa Numune Research and Training Hospital, Istanbul, Turkey

Phone (Telefon): +90 5056837557 E-mail (E-posta): pataraa96@gmail.com

Submitted Date (Başvuru Tarihi): 10.12.2017 Accepted Date(Kabul Tarihi): 06.02.2018

Copyright 2018 Haydarpaşa Numune Medical Journal

This is an open access article under the CC BY-NC license (http://creativecommons.org/licenses/by-nc/4.0/). 
the urethra and vagina were obliterated with an approximately $2 \mathrm{~mm}$ wide orifice. The urethral entry could not be seen. The catheter was placed, it slipped into vagina (Fig. 1). Transrectal ultrasound examination revealed a $40 \times 50-\mathrm{mm}$ uterus with the endometrium resembling a line with a fluid collection in it. Bilateral ovaries were not observed. Pathology results of the specimens obtained from mons pubis and labia minora were also compatible with LS.

The patient was started with topical clobetasol propionate-containing ointment twice daily and topical estrogen once daily. The patient was able to urinate more easily during the first month of the follow-up period. The vagina was dilated up to $0.5 \mathrm{~cm}$, and the vulvar sulci started to become evident. The vaginal dilation was about $1.5 \mathrm{~cm}$ at 3 months of follow-up (Fig. 2). There was no need for regular dilation.

\section{Discussion}

LS is localized in the anogenital region in $85 \%-98 \%$ of cases. The disease peaks during the prepubertal and postmenopausal periods. It localizes on sulcus interlabialis, labia major, labia minor, clitoris and its surroundings, perineum, and perineal body. Often, the genital mucosa is not involved. The vagina and cervix almost always remain intact. Itching is the most obvious symptom. There may be pain in the presence of erosion and fissure. Dyspareunia is seen in the case of introital stenosis. LS can be also asymptomatic and

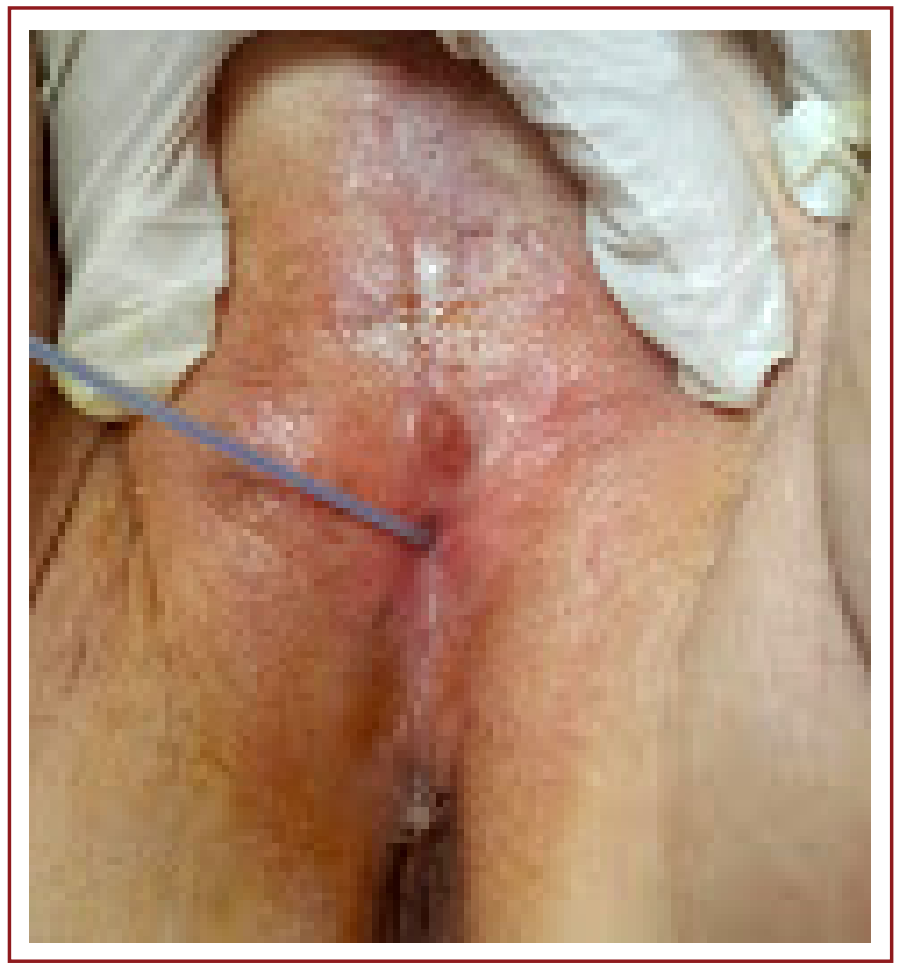

Figure 1. Pretreatment appearance of the lesion. can be detected by chance during genital examination. In infant girls, LS with anogenital lesion often manifests itself with itching and burning. Dysuria can also be seen. Also, perianal involvement is frequent in girls. Painful fissures cause constipation. Scar formation distorts the natural structure of the skin and anatomical region. Cicatrix formation may cause adhesions or even effacement of labia minora and can also lead to dysuria. The vestigial introitus in the vestibulum leads to constriction of the vaginal introitus and dyspareunia. Adhesions in the vicinity of clitoris also cause concealment of the clitoris. A painful pseudocyst may develop with the accumulation of keratinous debris in this region.

We present a quite advanced case of LS. The labium majus and minus were completely effaced and buried under the clitoral adhesions, and the vagina was completely obliterated. When we placed a 1-2-mm feeding tube through an orifice that we assumed to be urethral opening, we found that this was an obliterated vagina and the urethra was fused with anterior wall of vagina. The patient was able to urinate through vagina. In the literature, vaginal involvement has been very rarely reported in cases with vaginal stenosis. However, genital mucosa is preserved in classical involvement, and vaginal stenosis, as is in this case, develops as a result of labial fusion. Although vaginal dilatation is one of the treatment options that may be performed in advanced atrophic and fused cases like this one, if the uri-

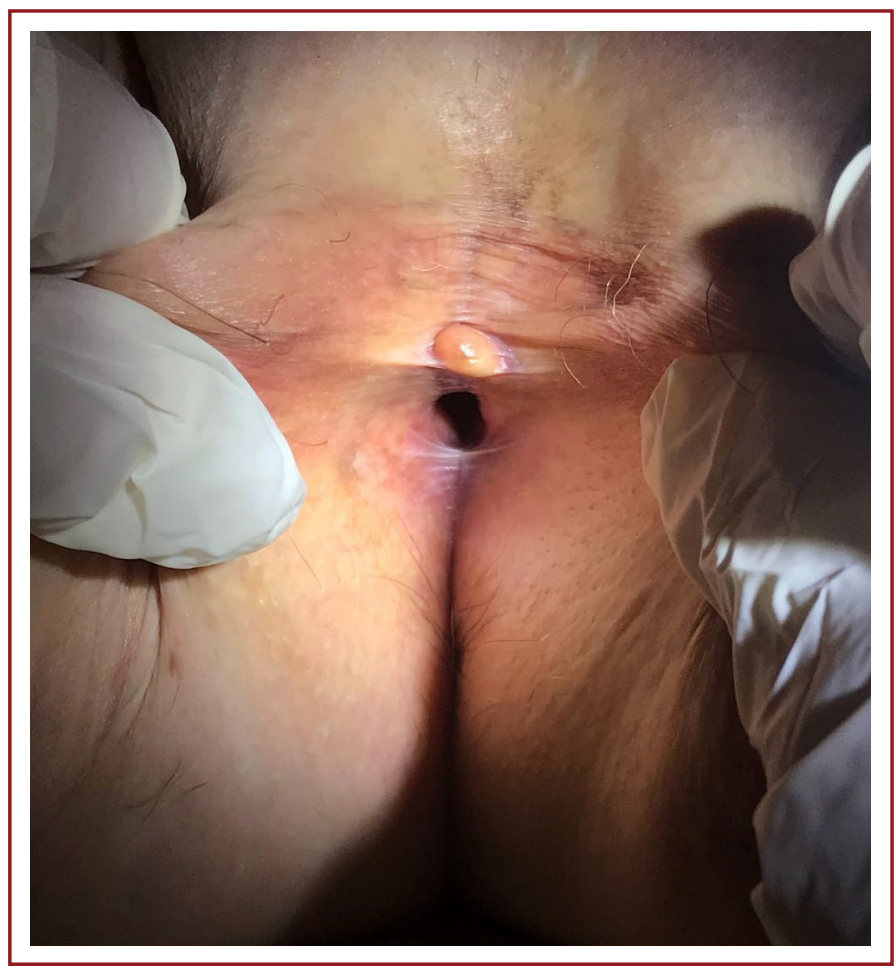

Figure 2. Appearance of the lesion at 3 months of follow-up. 
nary obstruction can be eliminated, we think that it is better to wait for the effects of medical treatment.

Treatment of LS is performed to relieve the complaints of itching, pain, dysesthesia, and so on, and to prevent formation of anatomic defects and complications. Besides, it is also suggested that malignant transformation may be prevented by suppression of the inflammatory process ${ }^{[7]}$. Patients with vulvar LS are at increased risk of developing SCC ${ }^{[8]}$. Potent and very potent topical corticosteroids, such as mometasone furoate $0.05 \%$ ointment and clobetasol propionate $0.05 \%$ cream, are considered as effective firstline treatment alternatives. Corticosteroids exert anti-inflammatory, antipruritic, and vasoconstrictive effects in LS. Clobetasol propionate has been found to be superior to placebo when used in vulvar LS for 3 months, and side effects such as susceptibility to infection, atrophy, and contact dermatitis have not been reported. The total dose of potent topical corticosteroids should not exceed $30 \mathrm{~g}$ within 12 weeks. Topical corticosteroids should be discontinued if no response is obtained despite regular follow-up and treatment for 6 months ${ }^{[7]}$.

Topical corticosteroids, particularly clobetasol propionate, are the gold standard for treatment. The opinions that the anti-inflammatory effect of mometasone furoate, which is a less potent topical corticosteroid, is stronger and has a longer duration of action may be an alternative to super potent topical corticosteroid therapy ${ }^{[9,10]}$. Although there is no consensus on the ideal treatment regimen for the administration of super potent topical corticosteroids, it is recommended that the patient should be initially treated for 6-12 weeks ${ }^{[10,11]}$.

Topical calcineurin inhibitors may be used as a second-line treatment. However, these drugs are more expensive than topical corticosteroids, and there is insufficient data on their long-term safe use. Topical progesterone and testosterone treatment have been shown to be less effective than clobetasol treatment ${ }^{[12-14]}$.

Betamethasone therapy with calcitriol, calcipotriene, and calcipotriene plus betamethasone may be effective in localized sclerotic events ${ }^{[15]}$. Triamcinolone acetonide injection of $20 \mathrm{mg}$ into thickened hypertrophic plaques per month for 3 months reduces patients' complaints ${ }^{[16]}$. Application of cryotherapy for genital lesions has also been shown to reduce symptoms. Laser therapy reduces symptoms but does not prevent recurrences. Retinoids decrease connective tissue degeneration. However, the use of these agents is limited due to their side effects such as cheilitis, xerosis, teratogenicity, elevated liver enzymes, elevated triglycerides, and alopecia ${ }^{[15]}$.
Hydroxycarbamide is an antineoplastic agent used in myeloproliferative diseases, and it inhibits the proliferation of $T$ lymphocytes and the production of gamma interferon. Administration of $1 \mathrm{~g}$ daily doses of hydroxycarbamide for 6 months in LS has been shown to reduce itching and pain [17]. Vitamin E supplementation and para-aminobenzoic acid have also been shown to reduce the complaints of patients ${ }^{[18]}$.

Adult patients should be informed about the increased risk of SCC. Patients diagnosed with LS should be aware of the possibility of disease in other family members. If LS is thought to be related to autoimmune diseases; autoantibody and thyroid scanning should be done in case of clinical necessity. Taking pictures to evaluate the progression of the disease may be helpful ${ }^{[19]}$. In addition, pelvic examination, and inspection and palpation of vulva should be thoroughly performed. Palpable masses and ulcerations in the vulva and inguinal region and discolorations in the lesions should be evaluated, and biopsy material should be taken from the lesions that lead to the suspicion of vulvar cancer. Typically, SCC lesions are in the form of papules, nodules, or plaques, which may be solid, white, red or the same color as the skin. Erosion and ulceration may be seen at varying degrees.

Here, we shared the dramatic response of our patient who presented with advanced anatomic defects to the first-line topical treatment. However, it should be noted that this disease is a chronic event and that patients should be regularly followed up concerning the development of vulvar cancer.

Informed Consent: Written informed consent was obtained from the patient for the publication of the case report and the accompanying images.

Peer-review: Externally peer-reviewed.

Conflict of Interest: None declared.

Authorship Contributions: Concept: N.A., F.V.; Design: F.V., N.A.; Data Collection or Processing: F.V., P.G.G.; Analysis or Interpretation: F.V., S.A.A.; Literature Search: S.A.A.; Writing: S.A.A.

Financial Disclosure: The authors declared that this study received no financial support.

\section{References}

1. McPherson T, Cooper S. Vulval lichen sclerosus and lichen planus. Dermatol Ther 2010;23:523-32. [CrossRef]

2. Farrell AM, Millard Pr, Schomberg KH, Wojnarowska F. An infective aetiology for lichen sclerosus: Myth or reality? Br J Dermatol. 1997;137:25.

3. Neill SM, Staughton RCD, Lane EB, Leigh IM. The cytokeratin profile of normal vulval epithelium and vulval lichen sclero- 
sus. Br J Dermatol 1990;123:62. [CrossRef]

4. Thomas RH, Ridley CM, McGibbon DH, Black MM. Anogenital lichen sclerosus in women. J R Soc Med 1996;89:694-8.

5. Black MM, McKay M, Braude P. Color atlas andtext of obstetric and gynecologic dermatology. London; Mosby Wolfe; 1995. p. 119.

6. Uludag S, Mat C, Gezer A, Simsek A, Altınok T. Lichen Sclerosus Complicated by Vaginal Stenosis: Diagnosis and Management. J Turkish-German Gynecol Assoc 2008;9:176-8.

7. Ergin Ş. Lichen Sclerosus. Turk J Dermatol 2012;6:27-34. [CrossRef]

8. Thomas RH, Ridley CM, McGibbon DH, Black MM. Anogenital lichen sclerosus in women. J R Soc Med 1996;89:694-8. [CrossRef]

9. Virgili A, Borghi A, Toni G, Minghetti S, Corazza M. First randomized trial on clobetasol propionate and mometasone furoate in the treatment of vulvar lichen sclerosus: results of efficacy and tolerability. Br J Dermatol 2014;171:388-96.

10. Funaro D, Lovett $A$, Leroux N, Powell J. A double-blind, randomized prospective study evaluating topical clobetasol propionate $0.05 \%$ versus topical tacrolimus $0.1 \%$ in patients with vulvar lichen sclerosus. J Am Acad Dermatol 2014;71:84-91.

11. Goldstein AT, Creasey A, Pfau R, Phillips D, Burrows LJ. A double-blind, randomized controlled trial of clobetasol versus pimecrolimus in patients with vulvar lichen sclerosus. J Am Acad Dermatol 2011;64:e99-104. [CrossRef]

12. Bracco GL, Carli P, Sonni L, Maestrini G, De Marco A, Taddei
$\mathrm{GL}$, et al. Clinical and histologic effects of topical treatments of vulval lichen sclerosus. A critical evaluation. J Reprod Med 1993;38:37-40.

13. Bornstein J, Heifetz S, Kellner Y, Stolar Z, Abramovici H. Clobetasol dipropionate $0.05 \%$ versus testosterone propionate $2 \%$ topical application for severe vulvar lichen sclerosus. Am J Obstet Gynecol 1998;178:80-4. [CrossRef]

14. Cattaneo A, De Marco A, Sonni L, Bracco GL, Carli P, Taddei GL. Clobetasol vs. testosterone in the treatment of lichen sclerosus of the vulvar region. [Article in Italian]. Minerva Ginecol 1992;44:567-71.

15. Nair PA. Vulvar Lichen Sclerosus et Atrophicus. J Midlife Health 2017;8:55-62. [CrossRef]

16. Mazdisnian F, Degregorio F, Mazdisnian F, Palmieri A. Intralesional injection of triamcinolone in the treatment of lichen sclerosus. J Reprod Med 1999;44:332-4.

17. Tomson N, Sterling JC. Hydroxycarbamide: a treatment for lichen sclerosus? Br J Dermatol 2007;157:622. [CrossRef]

18. Han JH, Choi HK, Kim SJ. Topical TRPM8 agonist (icilin) relieved vulva pruritus originating from lichen sclerosus et atrophicus. Acta Derm Venereol 2012;92:561-2. [CrossRef]

19. Kirtschig G, Becker K, Günthert A, Jasaitiene D, Cooper S, Chi CC, et al. Evidence-based (S3) Guideline on (anogenital) Lichen sclerosus. J Eur Acad Dermatol Venereol 2015;29:e1-43. 